\title{
SCIENCE IN UNITED STATES UNIVERSITIES
}

\begin{abstract}
A SURVEY of scientific research activities at colleges and universities in the United States, published by the National Science Foundation as No. 6 of "The Reviews of Data on Research and Development", gives the number of scientists and engineers employed in the natural and social sciences during the academic year 1953-54 as 70,000 .

Detailed information was obtained from 180 out of 190 institutions constituting almost all the schools granting advanced degrees in science, and more limited information was obtained from 807 out of the remaining 930 schools. The returns covered 62,251 or 90 per cent of the total, and of these 31,435 were engaged in research, 8,262 being full-time, the total full-time equivalent being estimated as 16,534. Of these latter, 5,481 were engaged in research $(2,281$ in engineering sciences, 1,077 in chemistry, 837 in physics), 3,508 in biological sciences, 2,171 in chemical sciences, 3,658 in agricultural sciences, 389 in psychology, and 1,327 in social sciences.
\end{abstract}

The 180 larger institutions reported 24,000 supporting personnel, corresponding to a full-time equivalent of 15,060 , giving a ratio of approximately $1: 1$. Of the 46,500 faculty members in the natural and social sciences at the 180 larger institutions, about 37,500 were employed full-time, and two-thirds of all the faculties spent some time on resesrch, representing two-fifths of the total faculty-time, whereas in 807 small institutions less than 2 per cent of faculty-time was devoted to research, less than 10 per cent, or 16,000, employed being engaged in research.

Nearly 1,500 professional schools were reported by the 987 institutions, of which 764 were in arts and sciences, 131 engineering, 106 health, 71 agriculture, 217 research organizations (mainly responsible for a particular field of research) and 263 other professional schools. Two-thirds of the institutions were private and the remaining public-controlled institutions employed 56 per cent of the total engaged in the natural and social sciences, 61 per cent of which were engaged in research.

\section{STARLING ROOSTS}

\begin{abstract}
A FASCINATING account of the way in which starlings roost and the sites they choose has been given by H. A. S. Key in the Bedfordshire Naturalist $(11 ; 1957)$. Starlings are abundant in Bedfordshire, and the many resident birds are considerably augmented during the winter months by many thousands of others which arrive chiefly from Scandinavia. At night the birds congregate in communal roosts which are usually sited in thorny copses and spinneys. In general, once a roost has reached an optimum condition of growth and nondisturbance, it is used for many seasons. At each roost the pattern of assembly is much the same. The birds fly at first in leisurely stages towards the roost, but as the daylight fades and they get nearer to the point of assembly, their flights are more direct and flocks tend to converge and amalgamate.

The point of assembly is close to the roosts and often on the ground, where the birds form a dark carpet and the noise of their whistling and chattering is considerable. Then, suddenly, they get up, often indulging in some preliminary aerobatics, first in
\end{abstract}

extended and then in close formation, before the entire party moves in a steady stream into the roost proper. Here with a great deal of commotion they wheel around and settle on the trees. For a short period there may be changes of perching areas within the roosting wood, but finally, when it is almost dark, the whole mass of birds is assembled in the regularly used part and then as each stem becomes packed with the jostling mass the din reaches its crescendo. From this tight grouping they are then not easily disturbed and sharp noises such as handclapping usually only suffice to cause the nearest group to move a few yards away.

In north Bedfordshire it would appear that the majority of the birds frequent one or other of two very large roosts, the populations of which would be hard to determine. These are Horn Wood, near Bozeat, Northants, just outside the west boundary of the county, and another site near Everton in the east. There was some years ago a smaller roost in Keysoe Park Wood, but this seems to have been abandoned.

\section{THE NATIONAL TRUST ANNUAL REPORT, 1956-57}

HE sixty-second annual report of the National
Trust, for 1956-57, makes slight reference to the
threats offered to its primary duty of ensuring the
safety of fine open country or fine buildings which
arise from Government departments or other public
authorities. Some evidence is recorded of increasing
public appreciation : in 1956 nearly 900,000 visitors
paid for admission to those properties where an
entrance fee is charged, an increase of more than
200,000 on 1955 , and membership increased by more than 5,500 to 61,713 , with a further increase of 3,740 during the first seven months of 1957 .

Nevertheless, the Council's hope that the 100,000mark will be reached in 1959 seems modest indeed and far too low, either to relieve the Council of continuing financial anxiety (in spite of a small surplus in 1956, when membership income incressed by $f 17,000$ ) or to ensure the widespread public 